\title{
Compartment syndrome and regional anaesthesia: Critical review
}

\author{
Jozef Klucka ${ }^{a}$, Petr Stourac ${ }^{\mathrm{a}}$, Alena Stouracova ${ }^{\mathrm{b}}$, Michal Masekc, Martin Repko ${ }^{\mathrm{d}}$
}

\begin{abstract}
Acute compartment syndrome (ACS) is a potential orthopaedic/traumatology emergency. Without prompt, precise diagnosis and immediate treatment with surgical decompressive fasciotomy it can lead to neurological dysfunction and disability. The role of regional anaesthesia (RA) in patients at risk for ACS/ and in those with developed ACS is controversial. The aim of this critical review was to answer the question, whether regional anaesthesia can delay the diagnosis. The authors use an evidence-based approach to discuss these high risk patients in considering RA as a method of choice for effective analgesia.

To the date of data collection, there was no single case report identified where RA alone led to delay in ACS diagnosis and surgical treatment. In four clinical cases, epidural analgesia can be associated with delayed ACS diagnosis. Frequent clinical evaluation and breakthrough pain despite a functional RA in combination with intracompartment pressure measurement remains the keystone of recommended management for patients at risk of ACS.
\end{abstract}

Key words: compartment syndrome, regional anaesthesia, peripheral nerve block/blockade

Received: December 16, 2016; Accepted: May 5, 2017; Available online: May 24, 2017

https://doi.org/10.5507/bp.2017.025

${ }^{a}$ Department of Paediatric Anaesthesiology and Intensive Care Medicine, Faculty of Medicine, Masaryk University and University Hospital Brno, Jihlavska 20, 62500 Brno, Czech Republic

${ }^{b}$ Department of Radiology, Faculty of Medicine, Masaryk University and University Hospital Brno, Jihlavska 20, 625 00 Brno, Czech Republic 'Department of Traumatic Surgery, Faculty of Medicine, Masaryk University and University Hospital Brno, Jihlavska 20, 62500 Brno, Czech Republic

${ }^{d}$ Department of Orthopaedic Surgery, Faculty of Medicine, Masaryk University and University Hospital Brno, Jihlavska 20, 62500 Brno, Czech Republic

Corresponding author:Petr Stourac, e-mail:petr.stourac@gmail.com

\section{INTRODUCTION}

Compartment syndrome (CS) is a clinical condition where increase in pressure within a closed compartment leads to perfusion abnormalities, ischemia and neurological damage. CS is considered a real orthopaedic/traumatology emeregency ${ }^{1}$. There are several pathophysiologic theories for describing this syndrome including the arteriovenous gradient theory and the ischemia-reperfusion syndrome ${ }^{2}$. However, whether there is a extraluminal or intraluminal pressure increase, the main principle remains the same - the pressure increase leads to capillary blood flow restriction, decrease in tissue $\mathrm{pO}_{2}$ and consequently to tissue hypoxia and ischaemia ${ }^{2}$. The pressure elevation in the compartment can arise from the inflammatory response, oedema, haemorrhage or ischaemia reperfusion syndrome, arterial pathology and also from external compression from casts, tight bandages, dressings or burns ${ }^{3-5}$. $\mathrm{CS}$ has been diagnosed in a variety of anatomical compartments including leg, gluteal region, thigh, tibia, foot, arm, forearm, hand and abdomen ${ }^{4}$. Fractures of the long bones, predominantly tibia (diaphysis) are the cause of approximately $75 \%$ of ACS and the risk is even higher in the case of comminuted fractures ${ }^{6-7}$. Soft tissue injuries without fracture represent the cause of around 20\% of ACS. The reported incidence of ACS is 3.1 per 100 000, and ten times higher in $\mathrm{men}^{8}$. The incidence in the paediatric population is even lower although due to physiologic higher intracompartment pressure $(13-16 \mathrm{mmHg}$ vs. $0-10 \mathrm{mmHg}$ ) children are at greater risk of ACS (ref. $\left.{ }^{9}\right)$. Identified risk factors for ACS are: male gender, young age $<35$ years, open fracture, intramedullary nailing, anticoagulation therapy, high-energy and penetrating trauma, vascular injuries, tourniquet use, haemophilia and complications of intravenous and intraosseous infusions ${ }^{8,10-19}$.

Prompt diagnosis of ACS is crucial and significantly lowers the morbidity. Clinical signs of ACS are known as 5/6P: pain out of proportion to injury and pain with acute stretch, pallor, pressure, paraesthesia, paralysis and pulselesness ${ }^{20-21}$. Pulselessness is not frequent, it is considered as a late $\operatorname{sign}^{22}$ and is associated with bad prognosis $22-24$. Clinical findings for ACS are however unreliable and can lead to delay in treatment ${ }^{5,25}$ because ACS can also present without any pain (in up to $10 \%$ of patients with ACS) $\left(\right.$ ref. $\left.{ }^{3,26}\right)$. The most reliable method for diagnosis seems to be frequent assessment of a patient's clinical condition combined with intracompartment pressure monitoring in high risk patients. Intracompartment pressure monitoring (ICP) is considered as a "gold standard" for ACS diagnosis and for decompressive fasciotomy indication ${ }^{5,14,16,24,27}$. The normal intracompartment pressure is in between 0-8 $\mathrm{mmHg}$ or below $10-12 \mathrm{mmHg}$ according to different data $^{9,28-30}$. Pain is common with the ICP pressure over $20 \mathrm{mmHg}$ and pressure over $30 \mathrm{mmHg}$ is considered to be indication for emergency fasciotomy ${ }^{8,10,27,31,32}$, but the precise value varies in the literature between $30-45 \mathrm{mmHg}^{33-34}$. 
Other authors recommend the $\Delta$ pressure - perfusion pressure $(\Delta$ pressure $=$ diastolic blood pressure - intracompartmental pressure) with a threshold of $30 \mathrm{mmHg}^{35}$. $\Delta$ pressure has been reported as more sensitive than the absolute measured pressure and can lead to minimizing the risk of unnecessary fasciotomy ${ }^{36-37}$. Data are consistent for the urgent indication for fasciotomy in ACS and it appears that performing the fasciotomy within 6 hours after diagnosis (after onset of ACS) is associated with good outcome - $88 \%$ good outcome, $3.2 \%$ amputation rate compared to fasciotomy after 12 hours - good outcome only in $15 \%$ of patients with $14 \%$ amputation rate ${ }^{38-39}$. The fasciotomy timing is not based on the robust evidence-based data (EBM) and neurological deficit can be diagnosed in cases with rapidly performed fasciotomy (in $2 \mathrm{~h}$ ). Hence, this seems to indicate fasciotomy as quickly as possible after confirmation of the ACS (ref. ${ }^{40}$ ).

Decompression with surgical fasciotomy is considered a gold standard for therapy CS. The timing of fasciotomy is important and the best functional results without neurologic consequences are achieved when fasciotomy is performed within six hours from onset of CS (ref. ${ }^{27}$ ). Regional anaesthesia (RA) is considered as a possible risk factor that can delay the diagnosis of acute CS (ACS) $\left(\right.$ ref. $\left.^{41-43}\right)$. Data are however derived only from case reports and case series and currently there is no uniform opinion in the literature or in clinical practice on the role of RA in patients in ACS or at in risk of ACS formation. Therefore, we decided to conduct the review of literature to answer whether the regional anaesthesia can lead to delay in diagnosis and treatment of ACS.

\section{RESULTS}

In the initial results we identified 294 citations, 88 were related to the topic: compartment syndrome and regional anaesthesia in the reviewed time period. After exclusion of duplicates $(n=56)$, articles not in English $(n=3)$ and articles with no available abstract or full-text online $(n=7)$ a total of 22 full-text articles were included in the final analysis: case reports $(n=15)$, review of literature $(n=5)$, clinical trial $(n=1)$, systematic review $(n=1)$. Search diagram is showed in Figure 1.

No randomized controlled study dedicated to the topic was found. The currently available published data are of low-EBM (evidence-based medicine) quality (case reports, case series, retrospective data) with the high risk of bias and that is the main limitation of this review.

In selected 15 case reports were 20 published clinical cases - Table 1 . The case reports were divided into 3 sections according to type of anaesthesia: regional anaesthesia, intravenous regional anaesthesia and epidural or subarachnoid/spinal anaesthesia and analgesia. No single case $(0 / 8)$ in regional anaesthesia subgroup was found to be related to delay in acute compartment syndrome (ACS) diagnosis. In 7 cases, breakthrough pain appeared despite functional regional analgesia and in 1 case there was swelling, blisters and passive extension excessive pain.

In the intravenous regional anaesthesia subgroup only two case reports were included in the review. In both, pain immediately (0-30 minutes after surgery) led to ACS diagnosis.

10 case reports were included in the epidural/spinal anaesthesia and analgesia subgroup. In 6 cases anaesthesia/analgesia did not lead to delay in ACS, because clinical signs of compartment syndrome were present despite functional blockade or the ACS appeared after a prolonged interval after epidural analgesia discontinuation. In 2 published cases Tang et al. ${ }^{44}$ and Somayaji et al. ${ }^{45}$ the epidural analgesia could have led to delay in ACS diagnosis however, in the first case there were some clinical signs of ACS - swollen calf, diminished capillary return. In the second case, dense block were persistent $24 \mathrm{~h}$ after epidural induction. In both cases the delayed diagnosis led to permanent neurological deficit. In Kumar et al. ${ }^{46}$ case 3 and case 4 , the pain appeared $4 \mathrm{~h}$ after epidural analgesia discontinuation. Epidural analgesia led to the delay. However there were clinical signs of ACS: erythema, tense and tender area and swelling in both patients. After urgent fasciotomy both patients fully recovered with no neurological deficit.

The only one included clinical trial (Maletis et al. ${ }^{47}$ ), compared the frequency of ACS in patients undergoing closed reduction of closed lower leg shaft fractures under general or intravenous regional anaesthesia. General anaesthesia had favourable effect with only $13 \%$ vs. $27 \%$ rate of ACS diagnosis. The reason for the higher incidence may be, according to the authors, explained by the thigh tourniquet use.

In the recently published systematic review by Driscoll et $\mathrm{al}^{48}$, the authors compared regional anaesthesia and the patient-controlled analgesia (PCA) in patients with compartment syndrome. Although they used different search methods and a different approach for considering the effect of anaesthesia and analgesia on the delay in ACS diagnosis, in 6/8 (75\%) patients in the PCA group ACS was diagnosed with a delay compared to the RA group where delay in diagnosis was detected in 19/29 (65\%) case reports (Table 1). When comparing the possible influence of RA on delay in time (considering the evolution in regional anaesthesia - lower dosing, lower concentrations, ultrasound guidance), the more recently published data (after 2009) claimed that in 75\% cases, no association between RA and delay in ACS was detected ${ }^{48}$.

\section{DISCUSSION}

Our results showed no relationship between functional regional anaesthesia and delay in ACS diagnosis. Intravenous regional anaesthesia can be associated with risk of ACS development, because the prolong and excessive cuff pressure can lead to ACS formation. However, currently, intravenous regional anaesthesia is used only occasionally. Regional continuous analgesia is considered superior to opioid-based analgesia and can lead to reduction of in-hospital stay and chronic pain incidence ${ }^{49}$. Regional anaesthesia (RA) in patients with ACS or in patients at risk is controversial, however we found no 


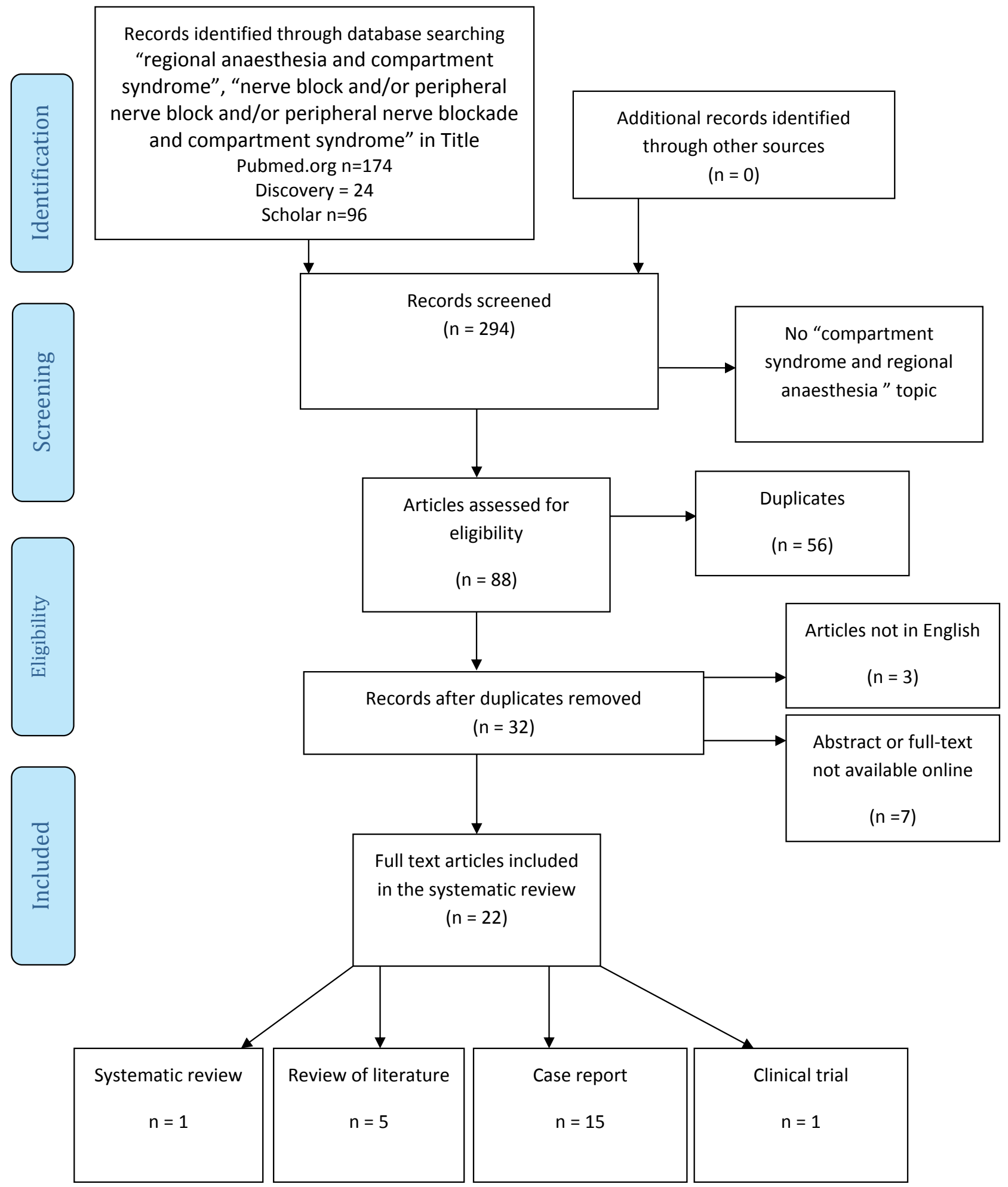

Fig. 1. Data search diagram.

published case report confirming that regional anaesthesia was the primary cause of the delay in ACS ( ref. $^{50-51}$ ), Aguiree et al. ${ }^{38}$ analysed 5 published case reports blaming RA for delay in ACS diagnosis, however in all cases the breakthrough pain was missed. From an ethical and pathophysiological point of view the patient's pain should be treated and there are several published case reports on opioid-based pain management has led to delay in ACS diagnostics $^{50-51}$. For this reason, the analgesic method per se cannot be considered as the reason for delay in diagnostics ${ }^{50,52}$. Cometa et al. ${ }^{53}$ and Walker et al. ${ }^{54}$ reported that despite functional continuous regional blockade, ischaemic pain was unaffected and patients can present with breakthrough pain.

It seems that compartment syndrome can be safely detected despite functional regional blockade ${ }^{55}$ and pa- 


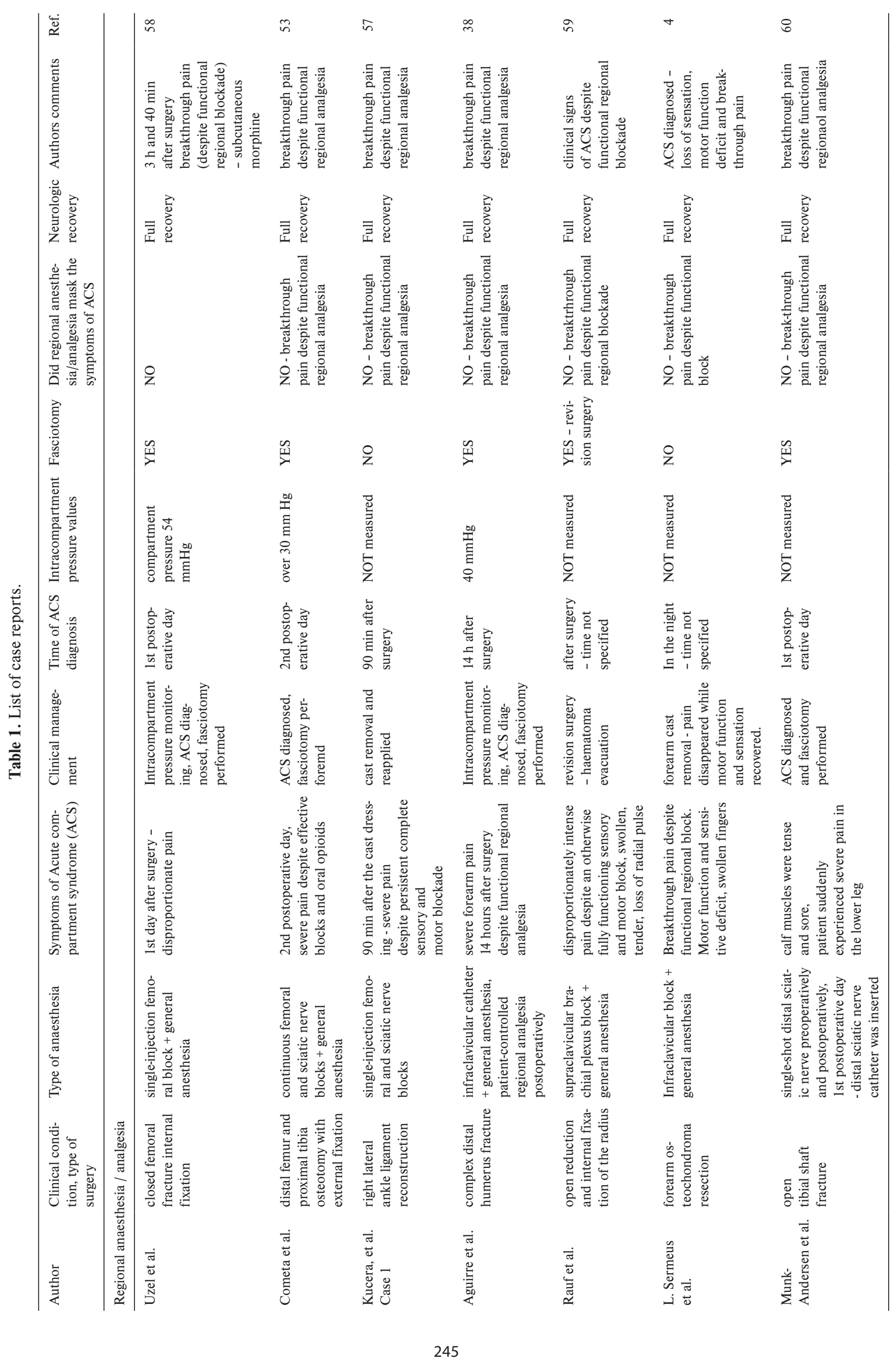




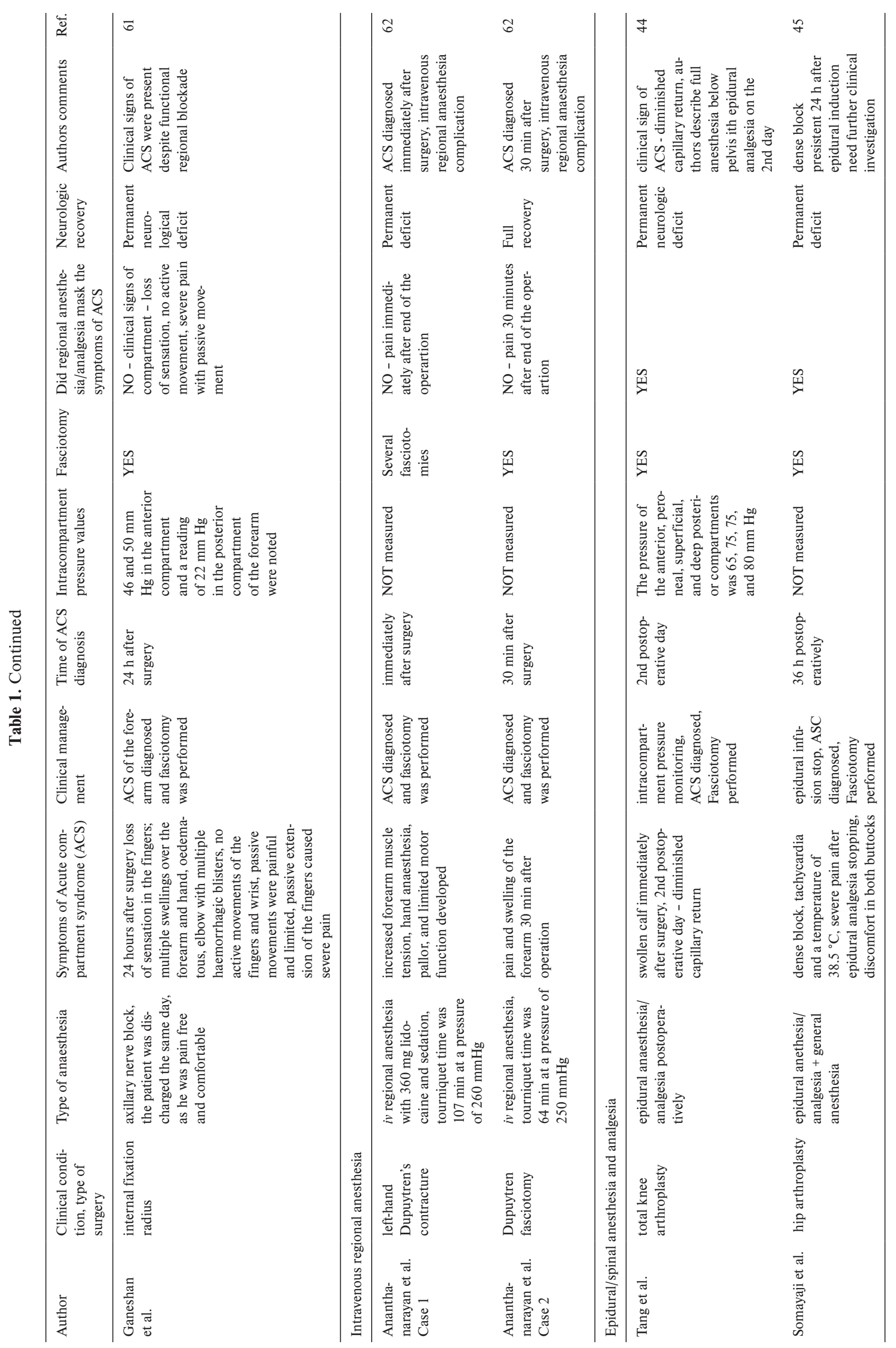




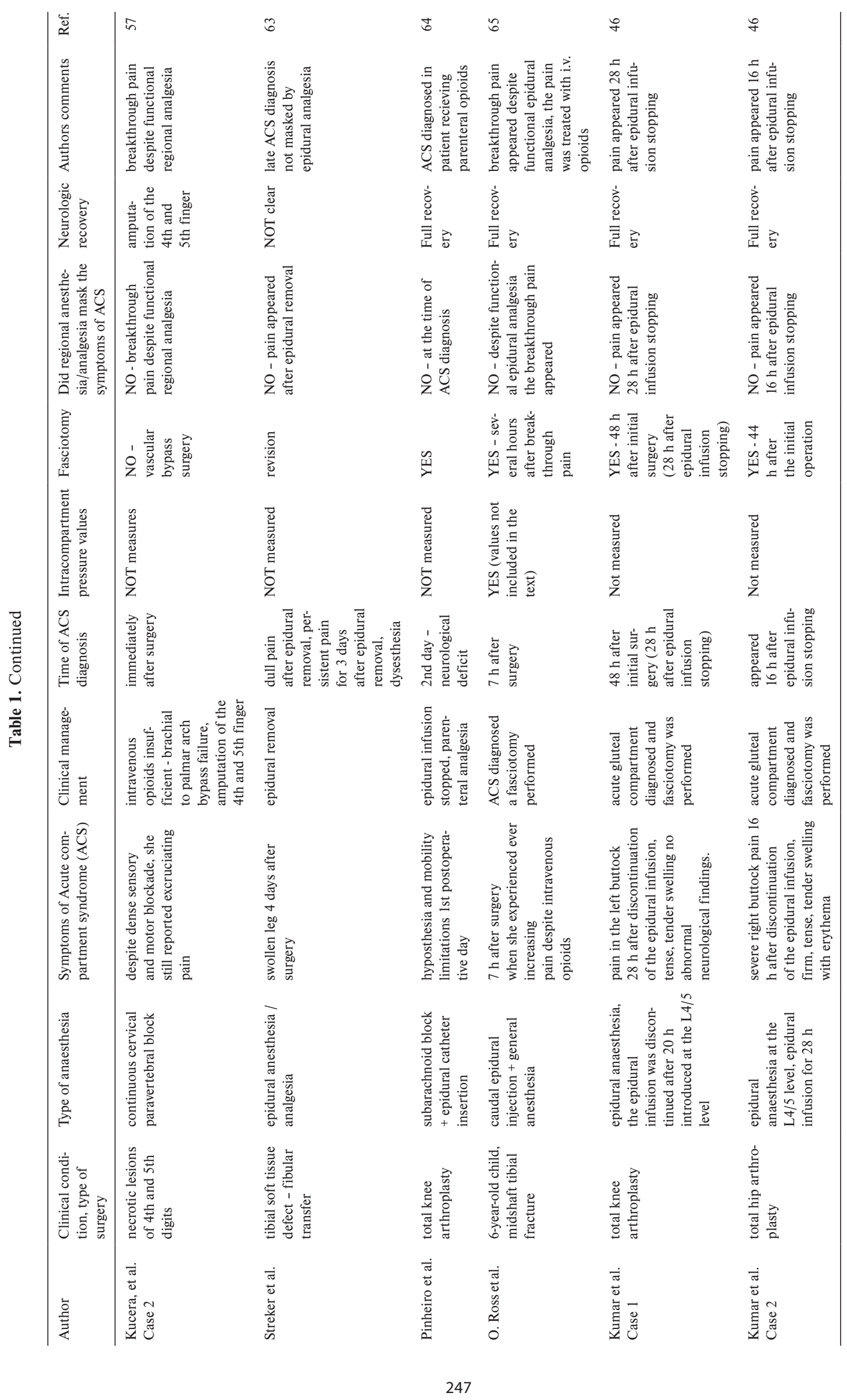




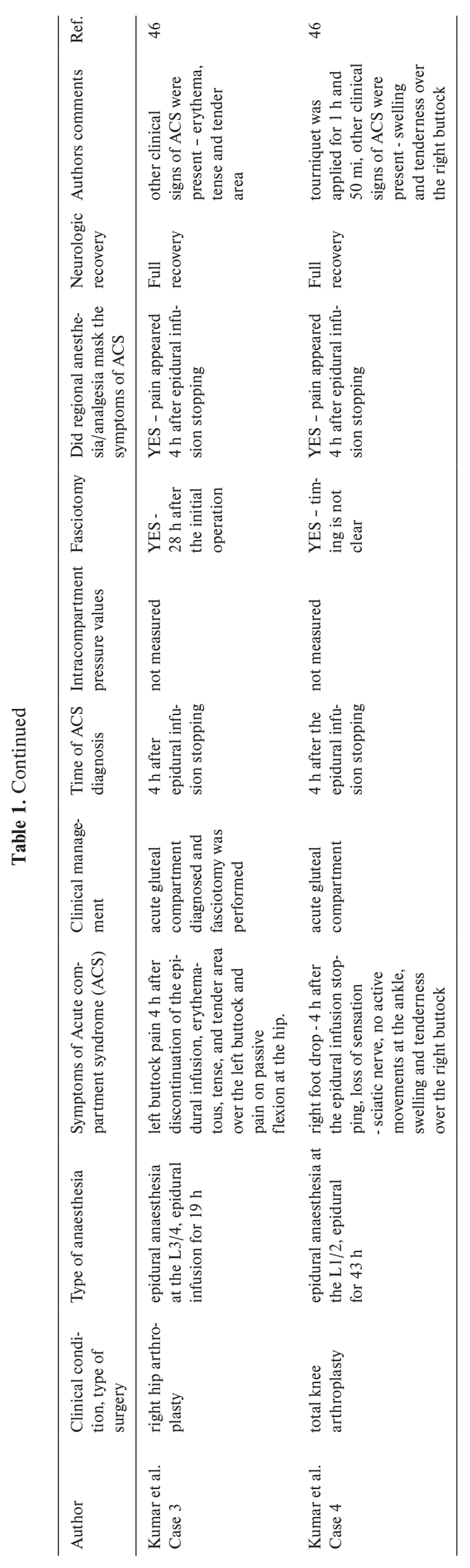


tients present with the classical signs of ACS (ref. $\left.{ }^{23}\right)$. The French Society of Anaesthesia does not consider the risk of ACS as a contraindication for regional anesthesia ${ }^{56}$ and because there is evidence that regional blockade can increase the blood flow through the partial sympathetic blockade without blocking the warning signs of ACS, the implementation of regional anaesthesia also in patients in the risk of ACS should be encouraged.

For minimizing the risk of delay ultrasound guidance for regional blockade and the catheter insertion, which can lead to lowering the dose of local anaesthetics are strongly recommended. Low concentrations of local anaesthetics can facilitate the motor function of the limb and allow breakthrough pain detection ${ }^{3,23,38,57}$.

Several cases (Kumar et al. ${ }^{46}$ ) reported, that epidural analgesia can lead to delay in ACS diagnosis, however the ACS is a complex syndrome and can present also without pain. In the majority of these cases there were other clinical signs of ACS presentation. These high-risk patients should be more frequently evaluated and intracompartment pressure measurement should be used. Frequent clinical re-evaluation of the patient's condition, increasing demands for analgesia and presence or reoccurrence of the breakthrough pain despite the functional RA should be incorporated in to management of the patient in the risk of ACS.

One interesting observation can be found in Driscoll et $\mathrm{al}^{48}$, that most of the articles pinpointing the delay in ACS diagnosis on RA were published in surgical/orthopaedic journals and most of the articles defending RA were published in anaesthesiology journals, which corresponds daily clinical practice.

Currently the EBM data considering the ideal analgesic method in patients with the risk of ACS is insufficient. Every single analgesic method can be associated with the delay in ACS diagnosis if pain is the sole diagnostic criteria. As opioids (PCA) can lead to even higher incidence of delay compared to regional anesthesia ${ }^{48}$ and it is highly unethical not to treat the pain, the complex management of the whole patient at risk of ACS appears to be more important than the analgesic method alone.

\section{Summary of evidence}

We found no prospective RCT dedicated to this theme and the reviewed data can be considered as low-EBM quality (case reports, case series). Currently clinical practice is based on several reported cases and the theme is considered controversial.

\section{Limitations}

The main limitation is sparse data of low quality, search strategy limited by 3 databases (PubMed, Scholar. google, EBSCO - Discovery) and inclusion only the articles in the English language.

\section{CONCLUSION}

Results of the review didn't show, that RA can be associated with higher risk in delay ACS diagnosis compared to other analgesic methods (intravenous opioid analgesia, epidural analgesia, PCA) and the cornerstone of diagnosis and treatment has to be the complex management including the intracompartment pressure monitoring in selected high-risk patient. Pain alone must not be considered as a single diagnostic sign of compartment syndrome.

However it must be noted that the evidence is spare and no clear guideline is currently available. There is an urgent need for discussion between orthopaedic/traumatology and anaesthesiology communities with the aim of establishing clear recommendation how to proceed in this clinical scenario.

\section{Search strategy and selection criteria}

This article followed the PRISMA Statement (www. prisma-statement.org) for meta-analysis and reviews.

We searched the following databases: Scholar Google (https://scholar.google.com), PubMed (http://www.ncbi. nlm.nih.gov/pubmed/), Discovery - EBSCO discovery service for keywords: regional, anaesthesia and compartment syndrome, nerve block or peripheral nerve block or peripheral nerve blockade and compartment syndrome located in the title or in the abstract.

We searched for data published between 1980 and 12/2016. All full-text articles in English related to the topic regional anaesthesia and compartment syndrome were included. Inclusion criteria were: articles found by selected search strategy (keywords, published between 1980-2016, selected databases), written in English language, full-text available and dedicated to the topic, compartment syndrome. Exclusion criteria were: abdominal compartment syndrome, articles not related to the topic $\mathrm{CS}$ and regional anaesthesia.

Acknowledgment: The article was published with the support by MZ ČR RVO (FNBr, 65269705) Czech Republic. Author contributions: JK, PS, AS, MM, MR designed the review, searched the articles in databases, interpreted findings, wrote the article and approved final text of the manuscript.

Conflict of interest statement: The authors state that there are no conflicts of interest regarding the publication of this article.

\section{REFERENCES}

1. Tzioupis C, Cox G, Giannoudis PV. Acute compartment syndrome of the lower extremity: an update. Orthopaed Trauma 2009;23(6):43340.

2. Janzing $\mathrm{H}$. Epidemiology, etiology, pathophysiology and diagnosis of the acute compartment syndrome of the extremity. Eur J Trauma Emerg Surg 2007;33(6):576-83.

3. Walker BJ, Noonan KJ, Bosenberg AT. Evolving compartment syndrome not masked by a continuous peripheral nerve block:evidencebased case management. Reg Anesth Pain Med 2012;37(4):393-7.

4. Sermeus L, Boeckx S, Camerlynck H, Somville J, Vercauteren M. Postsurgical compartment syndrome of the forearm diagnosed in a child receiving a continuous infra-clavicular peripheral nerve block. Acta Anaesthiol Belg 2015;66(1):29-32.

5. Mannion S, Capdevila X. Acute compartment syndrome and the role of regional anesthesia. Int. Anesthesiol Clin 2010;48(4):85-105. 
6. Elliott KG, Johnstone AJ. Diagnosing acute compartment syndrome. $J$ Bone Joint Surg Br 2003;85(5):625-32.

7. Harris $C$, Hobson $M$. The management of soft tissue injuries and compartment syndrome. Surgery 2015;33(6):251-6.

8. McQueen MM, Gaston P, Court-Brown CM. Acute compartment syndrome. Who is at risk? J Bone Joint Surg Br 2000;82(2):200-3.

9. Mossetti V, Ivani G. Controversial issues in pediatric regional anesthesia. Pediatr Anaesth 2012;22(1)109-14.

10. Blick SS, Brumback RJ, Poka A, Burgess AR, Ebraheim NA. Compartment syndrome in open tibial fractures. J. Bone Joint Surg 1986;68(9):1348-53.

11. Ferlic PW, Singer G, Kraus T, Eberl R. The acute compartment syndrome following fractures of the lower leg in children. Injury 2012;43(10):1743-6.

12. Park S, Ahn J, Gee AO, Kuntz AF, Esterhai JL.Compartment syndrome in tibial fractures. J. Orthopaed. Trauma 2009;23(7):514-8.

13. Tiwari A, Haq Al, Myint F, Hamilton G. Acute compartment syndromes. Br. J. Surg 2002;89(4):397-412.

14. Wall CJ, Lynch J, Harris IA, Richardson MD, Brand C, Lowe AJ, Suqrue M. Clinical practice guidelines for the management of acute limb compartment syndrome following trauma. ANZ J. Surg 2010;80(3):151-6.

15. Ojike NI, Roberts CS, Giannoudis P. Compartment syndrome of the thigh: a systematic review. Injury 2010;41 (2):133-6.

16. Ozkayin N, Aktuglu K. Absolute compartment pressure versus differential pressure for the diagnosis of compartment syndrome in tibial fractures. Int. Orthop 2005;29(6):396-401.

17. Wright EM. Neurovascular impairment and compartment syndrome: a literature review. Paediatr Nurs 2009;21(3):26-9.

18. Kalyani BS, Fisher BE, Roberts CS, Giannoudis PV. Compartment syndrome of the forearm: a systematic review. J. Hand Surg 2011;36(3):535-43.

19. Ali P, Santy-Tomlinson J, Watson R. Assessment and diagnosis of acute limb compartment syndrome:A literature review. International Journal of Orthopaedic and Trauma Nursing 2014;18(4):180-90.

20. Panchamia JK, Orebaugh S. Acute Compartment Syndrome and Regional Anesthesiology - What Residents on the Acute Pain Management Service Should Know. American Society of Regional Anesthesia and Pain Medicine [serial on the Internet]. 2013 November. Available from: https://www.asra.com/content/documents/nov-13_asra_news.pdf

21. Olson SA, Glasgow RR. Acute compartment syndrome in lower extremity musculoskeletal trauma. J Am Acad Orthop Surg 2005;13(7):436-44.

22. Tiwari A, Haq Al, Myint F, Hamilton G. Acute compartment syndromes. Br J Surg 2002; 89(4):397-412.

23. Mar GJ, Barrington MJ, McGuirk BR. Acute compartment syndrome of the lower limb and the effect of postoperative analgesia on diagnosis. British Journal of Anaesthesia 2009;102(1):3-11.

24. Kosir R, Moore FA, Selby JH, Cocanour CS, Kozar RA, Gonzalez EA, Todd SR: Acute lower extremity compartment syndrome (ALECS) screening protocol in critically ill trauma patients. J Trauma 2007;63(2):268-75.

25. Ulmer T. The clinical diagnosis of compartment syndrome of the lower leg: are clinical findings predictive of the disorder? J Orthop Trauma 2002;16(8):572-7.

26. O'Sullivan MJ, Rice J, McGuinness AJ. Compartment syndrome without pain! Ir Med J 2002;95(1):22.

27. McQueen MM, Christie J, Court-Brown CM. Acute compartment syndrome in tibial diaphyseal fractures. J Bone Joint Surg $\mathrm{Br}$ 1996;78(1):95-8.

28. Shadgan B, Menon M, O'Brien PJ, Reid WD. Diagnostic techniques in acute compartment syndrome of the leg. J. Orthop Trauma 2008;22(8):581-7.

29. Tuckey J. Bilateral compartment syndrome complicating prolonged lithotomy position. Br J Anaesth 1996;77(4):546-9.

30. Staudt JM, Smeulders MJ, van der Horst CM. Normal compartment pressures of the lower leg in children. J Bone Joint Surg Br 2008:90(2):215-9.

31. Mubarak SJ, Owen CA, Hargens AR, Garetto LP, Akeson WH. Acute compartment syndromes: diagnosis and treatment with the aid of the wick catheter. J Bone Joint Surg Am 1978;60(8):1091-5.

32. Matsen FA 3rd, Veith RG. Compartmental syndromes in children. J Pediatr Orthop 1981;1(1):33-41.
33. McHale PM, LoVecchio F. Narcotic analgesia in the acute abdomen a review of prospective trials. Eur J Emerg Med 2001;8(2):131-6.

34. Mubarak SJ, Pedowitz RA, Hargens AR. Compartment syndromes. Curr Orthop 1989; (3):36-40.

35. Whitesides TE, Haney TC, Morimoto K, Harada H. Tissue pressure measurements as a determinant for the need of fasciotomy. Clin Orthop Relat Res 1975;(113):43-51.

36. White TO, Howell GE, Will EM, Court-Brown CM, McQueen MM. Elevated intramuscular compartment pressures do not infl uence outcome after tibial fracture. J Trauma 2003;55(6):1133-8.

37. Garner AJ, Handa A. Screening tools in the diagnosis of acute compartment syndrome. Angiology 2010;61(5):475-81.

38. Aguirre JA, Gresch D, Popovici A, Bernhard J, Borgeat A. Case Scenario: Compartment Syndrome of the Forearm in Patient with an Infraclavicular Catheter. Anesthesiology 2013; 118(5):1198-205.

39. Hayakawa H, Aldington DJ, Moore RA: Acute traumatic compartment syndrome: A systematic review of results of fasciotomy. Trauma 2009;11(1):5-35.

40. Cascio BM, Pateder DB, Wilckens JH, Frassica FJ: Compartment syndrome: Time from diagnosis to fasciotomy. J Surg Orthop Adv 2005;14(3):117-21; discussion 120-1.

41. Dunwoody JM, Reichert CC, Brown KL. Compartment Syndrome Associated with Bupivacaine and Fentanyl Epidural Analgesia in Paediatric Orthopaedics. J Paediatr Orthop 1997;17(3):285-8.

42. Mubarak SJ, Wilton NC. Compartment syndromes and epidural analgesia. J Paediatr Orthop 1997;17(3):282-4.

43. Whitesides TE. Pain:friend or foe. J Bone Joint Surg Am 2001; 83$A(9): 1424-5$.

44. Tang WM, Chiu KY. Silent compartment syndrome complicating total knee arthroplasty: continuous epidural anesthesia masked the pain. J Arthroplasty 2000;15(2):241-3.

45. Somayaji HS, Hassan AN, Reddy K, Heatley FW. Bilateral gluteal compartment syndrome after total hip arthroplasty under epidural anesthesia. J Arthroplasty $2005 ; 20(8): 1081-3$.

46. Kumar V, Saeed K, Panagopoulos A, Parker PJ. Gluteal compartment syndrome following joint arthroplasty under epidural anaesthesia: a report of 4 cases. J Orthop Surg (Hong Kong) 2007;15(1):113-7.

47. Maletis GB, Watson RC, Scott S. Compartment syndrome. A complication of intravenous regional anesthesia in the reduction of lower leg shaft fractures. Orthopedics 1989;12(6):841-6.

48. Driscoll EB, Maleki AH, Jahromi L, Hermecz BN, Nelson LE, Vetter IL, Evenhuis S, Riesenberg LA. Regional anesthesia or patient-controlled analgesia and compartment syndrome in orthopedic surgical procedures: a systematic review. Local Reg Anesth 2016;6(9):65-81.

49. Richman JM, Liu SS, Courpas G, et al. Does continuous peripheral nerve block provide superior pain control to opioids? A meta-analysis. Anesth Analg 2006;102(1):248-57.

50. Harrington P, Bunola J, Jennings AJ, Bush DJ, Smith RM. Acute compartment syndrome masked by intravenous morphine from a patient-controlled analgesia pump. Injury 2000;31(5):387-9.

51. O'Sullivan ST, O'Donoghue J, McGuinness AJ, O'Shaughnessy M. Does patient-controlled analgesia lead to delayed diagnosis of lower limb compartment syndrome? Plast Reconstr Surg 1996;97(5):10878.

52. Richards H, Langston A, Kulkarni R, Downes EM, Does patient controlled analgesia delay the diagnosis of compartment syndrome following intramedullary nailing of the tibia? Injury 2004;35(3):296-8.

53. Cometa MA, Esch AT, Boezaart AP. Did continuous femoral and sciatic nerve block obscure the diagnosis or delay the treatment of acute lower leg compartment syndrome? A case report. Pain Med 2011;12(5):823-8.

54. Walker BJ, Noonan KJ, Bosenberg AT. Evolving compartment syndrome not masked by a continuous peripheral nerve block: Evidence-based case management. Reg Anesth Pain Med 2012;37(4):393-7.

55. Wu JJ, Lollo L, Grabinsky A. Regional anesthesia in trauma medicine. Anesthesiol Res Pract 2011; 2011: 713281. Published online 2011 Nov 21. doi: 10.1155/2011/713281

56. Soni S, Johannsson H. Does regional anaesthesia in trauma patients lead to delayed recognition of compartment syndrome? Br J Hosp Med (Lond) 2013;74(6):358.

57. Kucera TJ, Boezaart AP. Case Report Regional Anesthesia Does Not Consistently Block Ischemic Pain: Two Further Cases and a Review of the Literature. Pain Medicine 2014;15(2):316-9. 
58. Uzel AP, Steinmann G. Thigh compartment syndrome after intramedullary femoral nailing: possible femoral nerve block influence on diagnosis timing. Orthop Traumatol Surg Res 2009;95(4):309-13.

59. Rauf J, lohom G, O'Donnell B. Acute compartment syndrome and regional anaesthesia - a case report. Rom J Anaesth Int Care 2015;22(1):51-54.

60. Munk-Andersen H, Laustrup TK. Compartment syndrome diagnosed in due time by breakthrough pain despite continuous peripheral nerve block. Acta Anaesthesiol Scand 2013;57(10):1328-30.

61. Ganeshan RM, Mamoowala N, Ward M, Sochart D. Acute compartment syndrome risk in fracture fixation with regional blocks. BMJ Case Rep 2015 Nov 26;2015. pii: bcr2015210499. doi: 10.1136/bcr2015-210499.
62. Ananthanarayan C, Castro C, McKee N, Sakotic G. Compartment syndrome following intravenous regional anesthesia. Can J Anaesth 2000;47(11):1094-8.

63. Strecker WB, Wood MB, Bieber EJ. Compartment syndrome masked by epidural anesthesia for postoperative pain. Report of a case. .J Bone Joint Surg Am 1986; 68(9):1447-8.

64. Pinheiro AA, Marques PM, Sá PM, Oliveira CF, da Silva BP, de Sousa CM. Compartment syndrome after total knee arthroplasty: regarding a clinical case. Rev Bras Ortop. 2015;50(4):478-81.

65. Ross O. Central neural blockade and compartment syndrome. Anaesthesia 1999;54:297. 